\title{
Water resource formation and conversion and water security in arid region of Northwest China
}

\author{
CHEN Yaning ${ }^{1}$, LI Baofu ${ }^{1,2}$, LI Zhi ${ }^{1}$, LI Weihong ${ }^{1}$ \\ 1. State Key Laboratory of Desert and Oasis Ecology, Xinjiang Institute of Ecology and Geography, CAS, \\ Urumqi 830011, China \\ 2. College of Geography and Tourism, Qufu Normal University, Rizhao 276826, Shandong, China
}

\begin{abstract}
Climate change and water resource issues are global problems of common concern to the international community, and they are major bottlenecks affecting the eco-environment and sustainable socio-economic development in the arid region of Northwest China. On the basis of results from previous studies, this paper points out that the unique landscape of Northwest China increases the complexity and uncertainty of the climate system. This paper analyzes the key constraints on socio-economic development and ecological security in the region, discusses the impact of climate change on water resources in Northwest China, identifies common themes and the main problems present in research on climate change and water resources in the arid northwest region, and finally, based on the importance and urgency of conducting research on the region's water resources, proposes scientific problems that need to be addressed: first, the impact of climate change on the formation, conversion and future trends of water resources in the region; second, bidirectional coupling of high-resolution regional climate models and water cycle models of arid region land surface patterns; third, the impact of climate change and human activities on water resources of the arid northwest region. Through consideration and discussion of the above, this paper seeks to further clarify specific areas of research on pressing issues related to climate change and water resources in Northwest China, so as to establish a solid scientific basis for significantly enhancing our ability to respond to climate change and water shortages.
\end{abstract}

Keywords: climate change; water resources; arid areas; Northwest China

\section{The issues}

Global climate change is an important issue of common concern to the international community today. Climate change issues and the measures required to respond to climate change involve all aspects of the natural ecosystem and human life and production, and they have become major issues in contemporary human society that need to be resolved. The arid region of Northwest China is a mid-latitude zone in the hinterland of the Eurasian landmass

Received: 2016-04-25 Accepted: 2016-05-10

Foundation: National Natural Science Foundation of China, No.41471030, No.41501211

Author: Chen Yaning (1958-), Professor, specialized in studies on water resources and surface processes in arid regions. E-mail: chenyn@ms.xjb.ac.cn 
and an area sensitive to global climate change. In the past half century, the temperature of the arid northwest region has increased at a rate of $0.33-0.39^{\circ} \mathrm{C} / 10 \mathrm{a}$ (Zhang et al., 2010; Li et al., 2012), higher than the rest of China $\left(0.25^{\circ} \mathrm{C} / 10 \mathrm{a}\right)$ (Ren et al., 2005) and the global average $\left(0.14^{\circ} \mathrm{C} / 10 \mathrm{a}\right)$ (IPCC, 2013). In the arid northwest region, water resources are a key factor restricting socio-economic development and affecting ecological security, and they play a vital role in achieving sustainable socio-economic development in the future (Chen et al., 2016). Against the background of global warming, the arid northwest region, which relies on mountain precipitation and glacial meltwater as the basis of its water resource system, is extremely fragile, which is reflected by the marked increase in hydrological events (Sun et $a l ., 2014$ ), greater uncertainty over water resources and changes in the traditional rules governing the water cycle and eco-water demand. As the population rises and demand for water for socio-economic development increases further, the water resource issues facing the arid northwest region are set to worsen and their impact will deepen. At the same time, Northwest China is the source of a number of major international rivers, and instability of water resources caused by climate change has led to increased tensions between Central Asian countries. This constant conflict over water and the impact of climate change on the hydrological cycle are becoming focal points of international concern.

\subsection{Mountain and basin landform causing complexity and uncertainty in climate system}

The arid northwest region of China is characterized by basins and high mountains. The climate is deeply affected by the role of plateau uplift, westerly circulation and the East Asian monsoon, which creates a unique climate system made up of three basic geographical units, namely mountains, oases and deserts, and produces material migration and energy conversion processes mainly driven by water. The arid northwest region is vast, with complex regional topography and diverse ecosystems, including the lofty Tianshan, Altay, Kunlun and Qilian mountain ranges and the Gobi Desert. Unlike low-latitude subtropical arid zones, the unique arid northwest region is located at relatively humid latitudes, giving it a special and complex climate system. Research has shown that for almost 50 years the mountains, oases and deserts of Northwest China have experienced different changes in climate. This is mainly shown by differences in the speed of change in temperature and precipitation and in the timings of climatic jumps (Li B F et al., 2013). Similarly, even within the same ecosystem there are significant regional differences in climate change. For example, due to the tall barriers created by the terrain, the northern and southern slopes of the Tianshan Mountains have experienced differences in climate change (Wang et al., 2015).

The northwest region is also vulnerable to the impacts of global warming and human activities, and its climate system is unstable and extremely sensitive to global climate change. In recent 50 years, as the Earth's climate has warmed, temperatures have increased in the arid northwest region at a rate twice or three times, higher than the world average. As average levels of precipitation have fallen slightly in China, the northwest region's precipitation variability has increased, with a rise in precipitation overall. These unique changes in climate factors are closely linked to fluctuations in the Siberian High, Western Pacific Subtropical High, North American Subtropical High, Qinghai-Tibet Plateau Circulation and other atmospheric pressure systems (Li et al., 2012; Chen et al., 2014a; Li et al., 2016a), 
which are themselves inextricably linked to human activity. On the other hand, many scholars believe that the climate of the arid northwest region is becoming hotter and more humid, but temperatures over the past decade have fluctuated considerably while precipitation has decreased slightly, and it is unclear whether this indicates that the climate is becoming warmer and drier or warmer and more humid. On the whole, the climate of the arid northwest region is complex and characterized by considerable uncertainty.

\subsection{Water resources as a crucial factor restricting socio-economic development and ecological security}

The northwest region suffers from severe water shortages in the whole of China. The region covers an area of 2.5 million $\mathrm{km}^{2}$, has average annual precipitation of $230 \mathrm{~mm}$ and has evaporation capacity of $8-10$ times its precipitation level. It has approximately 110.9 billion $\mathrm{m}^{3}$ of water, or roughly $5 \%$ of China's total, and it has only $4.4 \times 10^{4} \mathrm{~m}^{3} / \mathrm{km}^{2}$ of groundwater, meaning it has a water shortage (Chen, 2014). Changes to water resources caused by climate change, whether in terms of quantity or spatio-temporal distribution, will result in greater conflict over the exploitation and utilization of water resources for striking a balance between maintaining the eco-environment and pursuing economic growth in the northwest region.

The shortage of water resources in the arid northwest region and the heterogeneity of their spatio-temporal distribution mean that the region's ecosystems are fragile. The majority of the ecological issues in arid areas are the result of an imbalance in water and salt levels caused by human activities. Northwest China is dominated by mountains and the Gobi Desert, with less than $10 \%$ of land area consisting of oases, with belts found along rivers and patches found in the wilderness surrounded by desert. Arid regions are often characterized by relatively abundant natural resources and an extremely fragile eco-environment, and the conflict between environmental protection and reconstruction and economic development in the course of exploiting water resources is always the core problem in water resource management in arid regions. Within the context of global warming, as population pressure increases and unsuitable land and water development activities continue, ecological and economic issues in the course of exploiting water resources will become increasingly acute in arid regions, and changes in the amounts and spatio-temporal distribution of water caused by climate change will possibly lead to greater conflict over supply and demand of water resources among oasis economies and desert ecosystems within river basins, leading to difficulties such as coordinating use of surface water and groundwater between oases and desert areas as conversion periods become less predictable. In terms of allocation of water resources, there is no clear method for scientifically allocating water for eco-water demand and water used in production within river basins, which threatens ecosystems and ecological security, so ecological and environmental issues caused by water are becoming increasingly prominent. The over-exploitation of water during the past three decades has caused desert vegetation to recede and damage to ecosystems. The eastern part of the lake at the mouth of the Heihe River and the western part of Juyanhai Lake have dried up; desertification is increasing, and the region has become a source of sandstorms; the water table has dropped significantly in the Shiyang River area, leading to deterioration in the eco-environment; and the 321-km long lower course of the Tarim River has dried up. The drying up of rivers has 
caused shrinkage and the disappearance of oases in their lower courses, leaving behind a series of ecological problems, including saline and alkaline soil, sandstorms and ecological refugees.

\subsection{Climate change intensifying water resource uncertainty}

The arid northwest region has extremely distinct characteristics of water resource formation and conversion, water cycle process and spatio-temporal distribution, which are representative of those found in arid regions around the world. Water resources in Northwest China all come from mountain precipitation and snowmelt, sources that are particularly sensitive to global climate change and which are subject to considerable uncertainty. Water formation in mountainous areas comes from high mountain snow and glacial meltwater, mid-mountain forest precipitation and low mountain bedrock fissure water. However, climate change has led to uncertainty regarding the processes of growth and decline of mountain glaciers and snow cover and spatio-temporal changes in precipitation, which means future water resource trends under climate change are unclear. Oases and deserts in flat plains are deprived of water, with different sources from water and land. Oases and desert ecosystems are affected by hydrological processes. The size of oases is determined by the volume of runoff from melting snow and glaciers and precipitation, and they are very sensitive to changes in hydrological processes and water conditions. Studies have shown that future climate change will lead to greater disparity between water resources and spatial distribution of productivity, which will intensify competition over water between ecological and economic uses (Chen et al., 2015).

The Fourth Assessment Report published by Working Group I of the IPCC stated that one of the most obvious results of climate change is a change to water cycles and corresponding changes to the runoff coefficient (IPCC, 2007). Particularly in the arid northwest region, various aspects of the water cycle have been significantly influenced by land surface patterns and climate. Water resources are complex, and there is considerable elasticity in runoff and water resources. Even relatively small changes in precipitation and temperature caused by climate change can cause significant changes in runoff and have a significant impact on eco-hydrological processes in arid areas. Changes to water cycles of mountainous areas caused by climate change exacerbate the instability of the water system. As such, the response of water resources and future trends in arid regions under climate change, as well as watershed surface water and groundwater water cycle processes and mechanisms, have become international focal points. There is, therefore, a need for systematic research of the effects of climate change on the water resources of the arid northwest region of China and scientific analysis of the water cycle of this unique region in order to improve our ability to respond to future climate change.

\section{Popular issues}

The water cycle systems of inland river basins in the arid northwest region of China are characterized by large differences in spatio-temporal distribution, complex and diverse runoff formations and conversions, and fragile water systems. Issues such as the effects of global climate change on future water supply and use structures and coordinated develop- 
ment of water, ecology and economy are core issues for water resource research and regulation in the northwest region.

\subsection{Water vapor sources and changing laws of the climate}

Terrain greatly influences the transfer of water vapor. Water vapor is the material basis of precipitation, and there is a close correlation between precipitation and external water vapor transfer and convergence. There is, therefore, a need to study the changing laws and mechanisms of climate and hydrological factors under the weak water vapor convergence conditions of the arid northwest region, with a focus on analysis of water vapor transfer and sources. Previous research (Lin and Zheng, 1997; Zhou, 2002; Dai et al., 2006) has shown that westerly weather systems and polar ice ocean systems are the main sources of water vapor transfer to northern and southern Xinjiang in China's northwest region, and in addition, the Hexi Corridor in the eastern section of Northwest China is also influenced by subtropical weather systems such as the East Asian monsoon and the southwest monsoons (Huan et al., 2015). The latest research (Li et al., 2016a) shows that when the North American Subtropical High and the Western Pacific Subtropical High are particularly strong, the Indian-Burma Trough deepens. Thus, southern airflow from across the equator, western airflow from the Indian Ocean and eastern airflow from the southern part of the Western Pacific Subtropical High converge to form southwest and southeast flows, respectively. These two airflows together supply a warm, moist airflow to the arid northwest region, which leads to more precipitation, or conversely, to less precipitation. It can be seen, then, that change in the strength of these atmospheric pressure systems and in the relationship between them determines the degree of water vapor transfer to the arid northwestern region and the spatio-temporal distribution of precipitation there, and it quantitatively determines the size of contribution to the arid region made by each water vapor path. This is extremely important for studying the changing law of precipitation and the frequency and intensity of extreme hydrological events.

\subsection{Glacier melt and glacial water changing trends}

The glacial melt inflection point occurrence time and the process and intensity of its effects on water resources in the arid northwest region are an important hot spot in the discussion of future water resource trends in the endorheic drainage basins of the region. Mountain glacial meltwater and precipitation are the main sources of many of the rivers in the northwest region, but glaciers are extremely sensitive to climate change, so the biggest impact of climate change on water resources is the effect it has on headwater glacial ice and snow reserves, which affects volumes of river runoff (Ma et al., 2010). As temperatures and precipitation have been increasingly affected by global warming in the 20th century, the majority of the glaciers around the world have retreated significantly, with a particularly rapid retreat taking place in the last 20 years (Wang et al., 2011). This change magnitude was completely unexpected and difficult to explain and predict using existing models. As a result, it is extremely urgent that we begin the search for new theories and methods for predicting changes in glacial runoff and the impact on future water resources. As the global climate changes and temperature rise, glacial meltwater will increase, meaning runoff from rivers that depend on meltwater will also increase. But the large number of small glaciers located at lower eleva- 
tions will disappear first as temperatures rise, and the supply of glacial meltwater to rivers will sharply decrease as glacier reserves decrease (Chen et al., 2014b).

Almost all the rivers in the arid northwest region originate in the mountains, and more than $85 \%$ of water resources are formed in high mountains surrounding basins, so glacial (and snow) meltwater and mountain precipitation are the main sources of water for inland rivers (Chen, 2014; Chen et al., 2015). Studies have shown that the arid northwest region is extremely sensitive to climate change. For example, between 1989 and 2012, the area of a glacier in the Karatal river basin in the western Tianshan Mountains shrank from $142.8 \mathrm{~km}^{2}$ to $109.3 \mathrm{~km}^{2}$, with a mean annual retreat rate of $1.02 \%$, which was much higher than other areas of the Tianshan Mountains (Kaldybayev et al., 2015). Another basic feature of inland river water resources in arid regions is that changes in ice and snow meltwater runoff are significantly restricted by temperature conditions of glacial areas (Deng et al., 2015), which is an issue in need of attention in studies on future glacier and water resource change.

\subsection{Impact of climate change on water cycle process}

Changes to the laws and mechanisms of the water cycle in the arid northwest region and the response processes they reveal are hot topics and key issues in research on regional climate change. In the past 50 years, a turning point of in the potential evapotranspiration trend occurred in 1993 in the arid northwest region, as the previous significant decline turned into a significant upward trend (Li Z et al., 2013; 2014). Research on the water cycle processes of the northwest region and responses to climate change tend to take mountain climate-hydrological processes, oasis farmland-hydrological processes and desert ecosystems-hydrological processes, as the major content, with river basin ecosystem hydrological processes constituting the main thread of research. Climate hydrological processes are non-linear complex systems with both definite and random features. The response of hydrological processes to climate change should possess multi-time and multi-space scale effect (Xu et al., 2014). In terms of time, a combination of non-linear approaches is needed to reveal the impact of climate change on hydrological processes in intra-annual, interannual, interdecadal and multi-interdecadal scales (Xu et al., 2014; Li et al., 2015). In terms of space, it is necessary to look at the relationship between climate change and mountain hydrological systems, agricultural systems of oases, groundwater in desert areas and vegetation systems, while integrating the unique features of water cycle processes, and to analyze the coupling relationship of mountains-oases-deserts and the spatio-temporal change characteristics in water cycle elements; consider regional differences in water cycle elements of river basins; identify the key factors that influence changes in water cycle elements of river basins; and interpret dynamic processes of inland river basin water cycles and the relationships between their various elements. Simulations of water cycle processes are an important direction being taken in contemporary water cycle studies, but there have been few studies on water cycles of the arid northwest region in China. Despite studies having been conducted on the atmosphere, surface water, groundwater and soil water processes of river basin water cycles, scale conversion and interface coupling difficulties mean that there have been relatively few studies on water cycle systems of river basins. There is a disconnect between basic research on water cycles and applied research on water resources, with a relative focus on macro water cycle processes in the arid northwest region and a lack of studies on the 
conversion relationship between water resource amounts and micro water cycle processes of ecosystems. There is a particular lack of in-depth studies for inland river basins in the arid northwest region on conversion mechanisms from mountain glacial and snow meltwater, mountain forest precipitation and surface water to groundwater, soil water and plant water, as well as quantitative laws.

\subsection{Water system vulnerability and the water security threshold}

The fundamental issue in water resource security is balancing supply and demand. The focus of research on water security in inland river basins of the arid regions is the intrinsic link between water from mountainous areas and the water required for living and production and by the ecosystem, as well as the dependency relationship within a river basin system between the volume of usable water and the volume of available water. Hydrological and water resource responses and vulnerability to global climate change have become important areas of research for the IPCC and other international organizations, including the AIACC project group, and research institutes (Leary et al., 2008).

Global climate change has exacerbated the conflict between water demand and supply in the arid northwest region, which has thrown into sharper relief issues such as the region's water supply and demand imbalance, increased variability in annual runoff, more extreme hydrological events and conflict between ecological and production water uses in the process of developing water resources. As far as research on water resource vulnerability is concerned, the majority of current studies in China focus on index systems for assessing water resource vulnerability, but do not include numerous factors, including changes in water resource supply, demand and management, in evaluation systems (Tang et al., 2000; Yin et al., 2008). Due to the complexity and non-linear nature of the systems, and a lack of theoretical research on identifying the factors of vulnerability key processes and its interaction, most studies only consider linear relationships and carry out quantitative vulnerability assessments of corresponding variables, resulting in considerable uncertainty over assessment results on resource vulnerability caused by climate change (Patt et al., 2005), and incomparability of established index systems (Polsky et al., 2007). There have been particularly few studies on vulnerability to abrupt climate change (Arnell et al., 2005). Introduction of the concept of key vulnerability and identification and selection of key vulnerability criteria in a report by the IPCC in 2007 provided an important basis for guiding future scientific assessments on the vulnerability of water resources to global climate change (IPCC, 2007). The influence of climate change on the vulnerability of water systems in the arid northwest region and determining water resource security thresholds under different scenarios are focal points for scholars now and for some time to come.

\subsection{Water resource allocation}

Assessing the impact of climate change on the processes and intensity of future water use for production, domestic water use and eco-water consumption is a core issue in determining water allocation in the complex "water-ecology-social economy" system of the arid northwest region (Chen, 2014). As global warming and population pressure increase, the conflict between water for production, living and the eco-environment will intensify. As glaciers melt even more as temperatures rise and precipitation in mountainous areas increases, the 
runoff from rivers that originate in the mountains and are fed by ice and snow meltwater will remain at a relatively high level for a certain period; however, as glaciers retreat even more, water reserves dwindle rapidly and glacial melt reaches an inflection point, available surface water resources from smaller glacial rivers will decrease suddenly, or suddenly increase due to abnormal rainfall variability. At the same time, higher temperatures may lead to greater water pollution problems (Mimikou et al., 2000; Patz, 2001), with water pollution exacerbating water resource tensions, intensifying the conflict between "water-ecology-social economy" in the arid northwest region. The pattern of the ecological and social landscape in the northwest region is determined by the spatio-temporal distribution of water resources, and the spatio-temporal distribution of volumes of water determines spatial configuration and functional zoning of ecosystems and socio-economic systems. In the past 50 years, economic development activities have significantly increased the area of artificial oases in the northwest region, and a trend for socio-economic focal points to move to the middle- and upper-reaches of rivers has emerged, resulting in the shrinkage of downstream lakes and rapid deterioration of desert riparian forest ecosystems (Li et al., 2015; Li Z et al., 2016).

"Water-ecology-social economy" issues arising in the course of developing water resources in the arid Northwest China are related to many natural and social factors. However, in previous studies, there has been a disconnect between research on natural factors and that on social factors, and there is a lack of overall consideration given to different scales of water use for socio-economic development and ecosystem water demand, as well as a lack of research on the link between water resource socio-economic service functions and ecosystem service functions in arid areas. There is a need to integrate the factors of "water-ecology-social economy" into one giant complex system, in order to comprehensively study the evolution of water cycle systems and the interactive relationship between socio-economic and eco-environmental systems; to analyze the impact of climate change on the processes and intensity of future water use for production, domestic water use and eco-water consumption; to reveal the evolving water resource laws due to climate change and the influence of human activities and the interactions between water and land use/cover change and socio-economic development (Nian et al., 2014); to scientifically assess changing water resource vulnerability under different climate change scenarios; to propose rational water resource allocation thresholds to ensure the sustainable development of ecosystems and the socio- economic system; and to adjust existing water utilization structures in view of future climate change, so as to mitigate future water vulnerabilities to climate change and reduce losses caused by climate change.

\section{Difficult issues}

The diversity of water resources, uniqueness of water cycle processes and complexity of ecological and economic processes in the development and utilization of water resources in the arid northwest region mean it is important and urgent to conduct water resource research in the region. In-depth research is required in the following three areas.

\subsection{Impact of climate change on the formation, conversion and future trends of water resources in arid areas}

Climate change increases the variability and uncertainty of rivers in the arid northwest re- 
gion, which are mainly supplied by ice and snow meltwater. As a result, the formation, conversion and future trends of water resources in the region all need to be analyzed along with the features, laws and trends of past, present and future climate change, starting with changes in climate factors that affect water resources and combining global changes. Using historical data, proxy data and regional climate models, the changing spatio-temporal features of climate and hydrological factors of inland river basins in the northwest region can be analyzed, the sequence of changes over a long time period can be discovered and analyzed, and future trends can be scientifically forecast. Historical hydro-meteorological data and remote sensing data should be used and a data assimilation method employed to establish a multi-scale hydro-meteorological data series, allowing investigation of changing laws, mechanisms and responses to climate change in climate and hydrological factors under weak convergence of water vapor in the arid northwest region, and analysis of the changing laws of, and statistical relationship between, temperature, precipitation, snow cover, runoff and evaporation under different temporal and spatial scales. A multi-scale, multi-method observational approach should be adopted, with environmental isotope and other environmental tracer techniques introduced (Sun et al., 2016), to establish a runoff division numerical model that can precisely divide the runoff elements of ice and snow meltwater from high mountains, precipitation from mid-mountain forests and bedrock fissure water (Fan et al., 2014); to investigate runoff formation, conversion mechanisms and water cycle processes; to analyze spatial differentiation characteristics; to quantitatively analyze quantitative conversion relations of high-mountain meltwater, mid-mountain forest precipitation and precipitation/meltwater-runoff/infiltration; and to analyze the root causes and mechanisms behind the formation of regional differences in water resources and their responses to climate change. There is also a need to combine future climate change scenarios, develop distributed hydrological models suited to mountains, oases and deserts of inland river basins, interpret the formation and conversion processes of water resources, quantitatively describe the relationship between the various components that form water resources at the river basin scale, and estimate the impact and future trends of climate change on water resources.

\subsection{Bi-directional coupling of high-resolution regional climate models and water cycle models of arid region land surface patterns}

The effect of climate change on societies, economies and eco-environment is an area of common concern among the international community. In order to positively respond to the challenges to human survival posed by climate change, scholars and government departments have begun researching attributes, effects and models of global climate change (Crowley, 2000; IPCC, 2013; Sun et al., 2010). Although the IPCC Fifth Assessment Report stated that important improvements had already been made in many aspects of climate model simulations of temperature and precipitation since the previous assessment report in 2007 (IPCC, 2013), the complexity and diversity of regional environments and atmospheric pressure systems mean that inevitable difficulties and drawbacks exist when it comes to study climate change on a global scale, and it is hard to give accurate descriptions and predictions of the hydrological processes of a region or a river basin using models of global atmosphere and water cycles. There are significant differences in the results of global climate models that attempt to simulate regional atmospheric changes (Jiang et al., 2010; 
Zhang et al., 2011), and simulation results are not fully applicable to the study of regional climate change. When using global models to analyze regional climate change they need to be adjusted for regional climate conditions. Global climate models need to be regionalized or regional climate models established (Ju et al., 2006; Li et al., 2009). Moreover, although the theoretical frameworks of atmospheric circulation models are largely similar, there are differences in their boundary settings and spatial resolutions, which often leads to uncertainties in their output results (IPCC, 2013), making it difficult to use them as basic data for regional and river basin hydrological models. Nor can they sufficiently describe regional climate features and calculated runoff processes (Boone et al., 2004), not to mention accurately reflect the actual dramatic change in climate factors in runoff areas and dissipation areas of river basins in the arid northwest region (Fang et al., 2015). Hydrologists and water resource managers are increasingly starting to focus on constructing regional climate models and studies on climate change (Montes-Hugo et al., 2009; Roy et al., 2011). The focus is on the effects of climate change on water cycle processes of river basins and regions, in the hope of obtaining relatively accurate hydrological parameters at relatively large scale spatial resolutions. However, because there is almost no river basin- or regional-scale data to directly estimate hydrological parameters, current river basin or regional water cycle models are obtained by adapting hydrological parameters to river basins or regions, or by extrapolating from information on physical attributes for regions with no data. Thus, hydrological simulations for river basins and areas in mountainous parts of the arid northwest region that do not have hydrological station data are a key and prominent scientific challenge in current hydrological studies. Although it is possible to use a modified Delta method to create a climatic reconstruction of meteorological data for high mountainous areas on the basis of the principle of similarity (Xue et al., 2015), considerable uncertainty regarding runoff simulations still exists. Thus, in order to accurately analyze regional climate change issues, it is necessary to clarify the interactive roles and mechanisms of regional atmospheric pressure systems and their effect on regional climate (Sanchez et al., 2011; Mahlstein et al., 2010). As such, it is particularly important to develop and apply research on regional climate models in order to correctly interpret regional climate change processes and future trends, rationally assess regional climate change impacts and accurately formulate strategies for responding to climate change. This is also the future trend in climate model development.

The arid northwest region's unique geographical location and topography mean that the formation and distribution of its water resources, as well as its water cycle processes, are different from China's eastern and other regions. At the same time, the influences of climate change and human activities on the water cycle in the region have been particularly noticeable, and there is no other region in the world with similar circulatory characteristics or water cycle processes as Northwest China; nor is there a region that can provide the northwest region with a mature example of how to develop its water resources. Because water production processes in the arid northwest region are largely concentrated in cold mountainous areas, where there are few meteorological and hydrological stations or, such stations are located in areas of lower altitude, if there are any, and the ground is frozen for much of the year in those areas, it is currently difficult for hydrological models to reflect the impact of frozen ground on runoff processes in mountainous runoff producing areas, which means simulation results are often less than perfect (Zhang et al., 2016). In addition, in the 
multi-objective calibration process for a distributed hydrological model, because there may be inconsistencies between objective functions, multi-objective optimization issues have become a hot topic in current hydrological studies (Yang et al., 2014). To this end, there is an urgent need to create a high-resolution arid area regional climate model based on a mountains-oases-deserts land pattern that integrates the features of the arid northwest region to investigate the control and influence the mountain and basin alternating landform and unique land surface patterns have on regional circulation. At the same time, it is necessary to consider comprehensively runoff production and dissipation, mountains and plains, and deserts and oases when producing land surface parameterization improvement programs; to develop a multi-scale and multi-objective hydrological model merging method; to construct a mountains-oases-deserts coupling, distributed regional water cycle model with land pattern features that fit arid areas and a river basin hydrological and water resource model based on mountain meltwater and precipitation. This allows quantitative identification of the impact of climate change and human activities on the water resource systems of arid areas (Li et al., 2016b; Shi et al., 2016), investigation of the possible major effects of spatio-temporal changes to water resources on socio-economic systems and ecosystems in arid areas, and predictions of scientific water cycle laws and water resource changing trends for arid areas.

\subsection{Effects of climate change and human activities on water security in the northwest region}

Climate change and human activities change water systems and affect water resource security. Studies on the effect of climate change on water resource security in the arid northwest region of China involve issues including river runoff processes, water availability and water demand under future climate change, as well as supply and demand imbalance caused by climate change (Liu et al., 2015). Thus, it is necessary to strengthen research on interactions and mechanisms of water inflow, availability and demand processes in the arid northwest region that integrates global changes, so as to construct a dynamic water system model with feedback mechanisms. There is also a need to carry out key vulnerability assessments of water systems in arid areas and research thresholds of water resource security management using hydrological landscape theory, vulnerability causal models and other methods to dynamically analyze key processes and vulnerabilities, and to understand the impact of climate change on various mechanisms of arid zones water systems and analyze the role of climate change and human activities in water resources. It is necessary to develop a dynamic model that comprehensively reflects the mutual feedback between water inflows, availability and demand; to analyze the impact of climate change and human activities on water inflow, availability and consumption processes; to identify key processes and key factors in maintaining water system stability and to analyze mechanisms of change; and to reveal key vulnerabilities of water systems and water security thresholds and their relation to climate change. In relation to the prominent conflict between ecology and economy in the development and utilization of water resources in the arid northwest region, and on the basis of an analysis of the hydrological, ecological and economic functions of water cycles within complex "water-ecology-social economy" systems, there is a need to carry out comprehensive research on response mechanisms to climate change of water cycles and water resources in arid areas and propose water management strategies for responding to climate change under 
coordinated ecological and economic development objectives. It is necessary, by developing and constructing water resource models suited to arid areas, to predict changes in future processes and intensity of water consumption for production and domestic use as well as eco-water consumption under climate change and socio-economic development scenarios, and to determine rational water resource allocation thresholds for "water-ecology-social economy" systems in arid areas. Finally, by analyzing the ability of water systems to adapt to climate change, and the degree to which they do so, as well as the impact of engineering techniques on the vulnerability of water systems, it will be possible to analyze water system stability and the relationship between socio-economic systems and ecological systems, explore the relationship between technological and economic input for adaptive control, and propose adaptive control countermeasures and models in response to climate change and for guaranteeing water resource security.

\section{References}

Arnell N, Tompkins E, Adger N et al., 2005. Vulnerability to abrupt climate change in Europe. Tyndall Centre Technical Report 34.

Boone A, Habets F, Noilhan J et al., 2004. The Rhone-Aggregation land surface scheme intercomparison project: An overview. Journal of Climate, 17(1): 187-208.

Chen Y N, 2014. Water Resources Research in Northwest China. New York: Springer. doi: 10.1007/978-94017-8017-9.

Chen Y N, Deng H J, Li B F et al., 2014a. Abrupt change of temperature and precipitation extremes in the arid region of Northwest China. Quaternary International, 336(12): 35-43.

Chen Y N, Li Z, Fan Y T et al., 2014b. Research progress on the impact of climate change on water resources in the arid region of Northwest China. Acta Geographica Sinica, 69(9): 1295-1304. (in Chinese)

Chen Y N, Li Z, Fan Y T et al., 2015. Progress and prospects of climate change impacts on hydrology in the arid region of Northwest China. Environmental Research, 139: 11-19.

Chen Y N, Li Z, Li W H et al., 2016. Water and ecological security: Dealing with hydroclimatic challenges at the heart of China's Silk Road. Environmental Earth Sciences. doi: 10.1007/s12665-016-5385-z.

Crowley T J, 2000. Causes of climate change over the past 1000 years. Science, 289(5477): 270-277.

Dai X G, Li W J, Ma Z G et al., 2006. The characteristics of Xinjiang water vapor source in recent years. Progress in Natural Science, 16(12): 1651-1656. (in Chinese)

Deng H J, Chen Y N, Wang H J et al., 2015. Climate change with elevation and its potential impact on water resources in the Tianshan Mountains, Central Asia. Global and Planetary Change, 135: 28-37.

Fan Y T, Chen Y N, Liu Y B et al., 2013. Variation of baseflows in the headstreams of the Tarim River Basin during 1960-2007. Journal of Hydrology, 487: 98-108.

Fang G H, Yang J, Chen Y N et al., 2015. Comparing bias correction methods in downscaling meteorological variables for a hydrologic impact study in an arid area in China. Hydrology and Earth System Sciences, 19(6): 2547-2559.

Huang W, Feng S, Chen J H et al., 2015. Physical mechanisms of summer precipitation variations in the Tarim Basin in northwestern China. Journal of Climate, 28(9): 3579-3591.

IPCC, 2007. Climate change 2007: Synthesis report. Contribution of Working Groups I, II and III to the Fourth Assessment Report of the Intergovernmental Panel on Climate Change. Cambridge, UK and New York, USA: Cambridge University Press.

IPCC, 2013. Working Group I Contribution to the IPCC Fifth Assessment Report, Climate Change 2013: The Physical Science Basis: Summary for Policymakers.

Jiang Y, Luo Y, Zhao Z C, 2010. Projection of wind speed changes in China in the 21 st century by climate models. 
Chinese Journal of Atmospheric Sciences, 34(2): 323-336. (in Chinese)

Ju L X, Wang H J, 2006. Modern climate over East Asia simulated by a regional climate model nested in a global gridpoint general circulation model. Chinese Journal of Geophysics, 49(1): 52-60. (in Chinese)

Kaldybayev A, Chen Y N, Vilesov E, 2015. Glacier change in the Karatal river basin, Zhetysu (Dzhungar) Alatau, Kazakhstan. Annals of Glaciology, 57: 11-19.

Leary N, Conde C, Kulkarni J et al., 2008. Climate change and vulnerability. Climate and Development, 1(1): $185-187$.

Li B, Zhou T J, Wu C Q et al., 2009. Relationship between rainfall and sea surface temperature simulated by LASG/ IAP AGCM and CGCM. Chinese Journal of Atmospheric Sciences, 33(5): 1071-1086. (in Chinese)

Li B F, Chen Y N, Chen Z S et al., 2016a. Why does precipitation in Northwest China show a significant increasing trend from 1960 to 2010? Atmospheric Research, 167: 275-284.

Li B F, Chen Y N, Shi X 2012. Why does the temperature rise faster in the arid region of Northwest China? Journal of Geophysical Research, 117: D16115.

Li B F, Chen Y N, Shi X et al., 2013. Temperature and precipitation changes in different environments in the arid region of Northwest China. Theoretical and Applied Climatology, 112(3/4): 589-596.

Li B F, Chen Y N, Xiong H G, 2016b. Quantitatively evaluating the effects of climate factors on runoff change for Aksu River in northwestern China. Theoretical and Applied Climatology, 123(1/2): 97-105.

Li B F, Chen Z S, Yuan X Z, 2015. The nonlinear variation of drought and its relation to atmospheric circulation in Shandong Province, East China. Peer J, 3: e1289.

Li Z, Chen Y N, Li W H et al., 2016. Potential impacts of climate change on vegetation dynamics in Central Asia. Journal of Geophysical Research, 120: 12345-12356.

Li Z, Chen Y N, Shen Y J et al., 2013. Analysis of changing pan evaporation in the arid region of Northwest China. Water Resources Research, 49: 2205-2212.

Li Z, Chen Y N, Yang J et al., 2014. Potential evapotranspiration and its attribution over the past 50 years in the arid region of Northwest China. Hydrological Processes, 28(3): 1025-1031.

Lin Z Y, Zheng D, 1992. The tracks of moisture transportation and its vapour geoecological characteristics on the Qinghai-Xizang Plateau. Arid Zone Research, 9(2): 1-7. (in Chinese)

Liu X R, Shen Y J, Guo Y et al., 2015. Modeling demand/supply of water resources in the arid region of northwestern China during the late 1980s to 2010. Journal of Geographical Sciences, 25(5): 573-591.

Ma L J, Zhao J F, Zang H J et al., 2010. Impacts of glacier and snow melting on Bosten Lake under climate change. Arid Land Geography, 33(2): 210-216. (in Chinese)

Mahlstein I, R Knutti, 2010. Regional climate change patterns identified by cluster analysis. Climate Dynamics, 35(4): 587-600.

Mimikou M, Blatas E, Varanaou E et al., 2000. Regional impacts of climate change on water resources quantity and quality indicators. Journal of Hydrology, 234: 95-109.

Montes-Hugo M, Doney S C, Ducklow H et al., 2009. Recent changes in phytoplankton communities associated with rapid regional climate change along the western Antarctic Peninsula. Science, 323(5920): 1470-1473.

Nian Y Y, Li X, Zhou J et al., 2014. Impact of land use change on water resource allocation in the middle reaches of the Heihe River Basin in northwestern China. Journal of Arid Land, 6(3): 273-286.

Patt A, Klein RJT, A dela Vega-Leinert, 2005. Taking the uncertainty in climate-change vulnerability assessment seriously. C R Geoscience, 337(4): 411-424.

Patz J, 2001. Public health risk assessment linked to climatic and ecological change. Human and Ecological Risk Assessment: An International Journal, 7: 1317-1327.

Polsky C, Neff R, Yarna B, 2007. Building comparable global change vulnerability assessments: The vulnerability scoping diagram. Global Environmental Change, 17(3/4): 472-485.

Ren G Y, Xu M Z, Chu Z Y et al., 2005. Changes of surface air temperature in China during 1951-2004. Climatic and Environmental Research, 10(4): 717-727. (in Chinese)

Roy T, Bopp L, Gehlen M et al., 2011. Regional impacts of climate change and atmospheric $\mathrm{CO}_{2}$ on future ocean carbon uptake: A multimodel linear feedback analysis. Journal of Climate, 24(9): 2300-2318. 
Sanchez E, Dominguez M, Romera R et al., 2011. Regional modeling of dry spells over the Iberian Peninsula for present climate and climate change conditions. Climatic Change, 107(3/4): 625-634.

Shi X L, Wang W, Shi W J, 2016. Progress on quantitative assessment of the impacts of climate change and human activities on cropland change. Journal of Geographical Sciences, 26(3): 339-354.

Sun C J, Chen Y N, Li X G et al., 2016. Analysis on the streamflow components of the typical inland River, Northwest China. Hydrological Sciences Journal, 2016, 61(5): 970-981.

Sun F B, Roderick M L, Farquhar G D et al., 2010. Partitioning the variance between space and time. Geophysical Research Letters, 37: L12704.

Sun G L, Chen Y N, Li W H et al., 2014. Intra-annual distribution and decadal change in extreme hydrological events in Xinjiang, northwestern China. Natural Hazards, 70(1): 119-133.

Tang G P, Li X B, Liu Y H, 2000. Assessment method of vulnerability of water resources under global climate change. Advance in Earth Sciences, 15(3): 313-317 (in Chinese)

Wang P Y, Li Z Q, Huai B J et al., 2015. Spatial variability of glacier changes and their impact on water resources in the Chinese Tianshan Mountains during the last five decades. Journal of Arid Land, 7(6): 717-727.

Wang S J, Zhang M J, Li Z Q et al., 2011. Glacier area variation and climate change in the Chinese Tianshan Mountains since 1960. Journal of Geographical Sciences, 21(2): 263-273.

$\mathrm{Xu} \mathrm{J}$ H, Chen Y N, Li W H et al., 2014. Integrating wavelet analysis and BPANN to simulate the annual runoff with regional climate change: A case study of Yarkand River, Northwest China. Water Resources Management, 28(9): 2523-2537.

Xue J, Gui D W, Lei J Q et al., 2015. Reconstructing meteorological time series to quantify the uncertainties of runoff simulation in the ungauged Qira River Basin using data from multiple stations. Theoretical \& Applied Climatology, 1-16. doi: 10.1007/s00704-015-1548-1.

Yang J, Castelli F, Chen Y N et al., 2014. Multiobjective sensitivity analysis and optimization of distributed hydrologic model MOBIDIC. Hydrology and Earth System Sciences, 18(10): 4101-4112.

Yang T, Wang C, Yu Z B et al., 2013. Characterization of spatio-temporal patterns for various GRACE-and GLDAS-born estimates for changes of global terrestrial water storage. Global and Planetary Change, 109: 30-37.

Yin Y, Clinton N, Luo B et al., 2008. Resource system vulnerability to climate stresses in the Heihe river basin of western China. Climate Change and Vulnerability, 2: 88.

Zhang F Y, Ahmad S, Zhang H Q et al., 2016. Simulating low and high streamflow driven by snowmelt in an insufficiently gauged alpine basin. Stochastic Environmental Research and Risk Assessment, 30(1): 59-75.

Zhang H F, Chen H S, 2011. Evaluation of summer circulation simulation over East Asia by 21 climate models. Part I: Climatology. Journal of the Meteorological Sciences, 31(2): 119-128. (in Chinese)

Zhang X Q, Sun Y, Mao W F et al., 2010. Regional response of temperature change in the arid regions of China to global warming. Arid Land Geography, 27(4): 592-599.

Zhou X J, 2002. The suggestion of exploitation and utilization of air water resources in Northwest China. In: 2002 Scientific Development Report. Beijing: Science Press. (in Chinese) 